\title{
Digital Library Development: a Case Study of Ta Quang Buu Library of Hanoi University of Science and Technology
}

\author{
Tran Thi Bich NGOC ${ }^{1}$, Duong Manh CUONG²*, Nguyen Thi NGAN ${ }^{3}$, Mai Thi UYEN ${ }^{4}$ \\ ${ }^{1,2,4}$ School of Economics and Management of Hanoi University of Science and Technology, Hanoi, Vietnam \\ ${ }^{3}$ Ta Quang Buu Library of Hanoi University of Science and Technology, Hanoi, Vietnam \\ *Corresponding author: cuong.duongmanh@hust.edu.vn
}

\begin{abstract}
\section{Research purpose:}

The purpose of the article is to introduce some theoretical issues of digital transformation related to the development of digital libraries and propose measures such as evaluating library users, creating digital collections from endogenous and exogenous sources, upgrading digital infrastructure of the library to enrich digital data sources for university's digital library
\end{abstract}

\section{Research motivation:}

The article aims to improve the service quality of the library of higher education institutions based on developing the university's digital library system by combining the existing traditional library with the digital library system as well as other databases in the country and abroad under the booming of digitalization and digital transformation.

\section{Research design, approach and method:}

The systematic literature review approach was applied in this study to briefly review the appearance and nature of the concepts of digital transformation; methods of comparative analysis and case study are used to analyze the survey data to find out the shortcomings of Ta Quang Bu Library in particular HEIs' libraries, and then discuss the obtained results to propose useful recommendations.

\section{Main findings:}

The case study of Ta Quang Buu Library of Hanoi University of Science and Technology shows that in order to improve service quality, it is necessary to focus on the characteristics and habits of users, and improve the capacity and skills of users. librarian, develop digital resources, finance IT infrastructure development as well as build database for E-learning in the long term in cooperation with other libraries and databases.

\section{Practical/managerial implications:}

The article focuses on the development of university digital libraries in the digital era and look at solutions to create digital libraries to improve the quality of library services.

Keywords: digitization, digitalization, digital transformation, digital library, information user, digital collection

\section{INTRODUCTION}

Under the impact of the Industrial Revolution 4.0, the trend of digital transformation (DT) towards the digital economy is taking place rapidly around the world. A study funded by Microsoft in 2017 shows that $85 \%$ of
Asia Pacific organizations surveyed in 2017 have embarked on their DT journeys. Whilst majority of these are still in early stages of DT, these organizations have experienced significant benefits in productivity, profit margin, cost reduction, customer loyalty, and revenue growth of up to $17 \%$. By 2021, 60\% of Asia Pacific's 
GDP will be derived from digital products or services created through DT. Over the same period, DT will add $0.8 \%$ annually to the region's GDP, or US\$1.16 trillion (Daniel-Zoe et al, 2017).

In Vietnam, many remarkable achievements have been made in the DT field in order to build a digital economy, digital community and digital society. The explosive growth of information and communication technologies (ICTs) accelerates the processes towards a knowledgebased economy and profoundly impacts the training process in universities and poses new challenges for universities, students and faculty as well (Torres-Ruiz et al, 2019). In the higher education system, the development of the digital university model is being confirmed by the benefits and opportunities it brings to higher education institutions (HEIs), becoming an inevitable trend while DT is taking place rapidly all over the world in all fields, in which education is the priority sector as it is directly related to human resource training. Moreover, the COVID-19 pandemic has been being protracted for a long time, affecting universities and pushing them accelerate the DT process, distance training and online training (e-learning). The development trend of digital university, in essence, is the DT process at different levels (Bui Thi Nga et al, 2020).

Aiming at the dual goal of developing a digital government, digital economy, and digital society, as well as forming Vietnamese digital technology enterprises with global competitiveness, the Government has approved the "National Digital Transformation Program by 2025, with a Vision toward 2030" (Decision No. 749/QD-TTg of the Government dated June 3, 2020), whereby, education is acknowledged as second priority sector among 8 priority areas for DT in Vietnam.

The content of DT in education is defined as developing digital technology platforms aimed at supporting remote learning, teaching and personalized training and managing university activities, digitalizing learning materials, establishing platforms for online sharing teaching and learning resources. The process of DT and formation of digital universities in higher education inevitably entails the development of digital libraries (DLs).

The purpose of the article is to examine theoretical issues related to the DT process and the developing university DL through analyzing the current situation of the Ta Quang Buu Library (TQBL) of Hanoi University of
Science and Technology (HUST) as a case study to propose practical solutions for the creation and development of universities' DL in general.

\section{LITERATURE REVIEW}

\section{Digitization, digitalization, digital transformation}

Digitization, digitalization and digital transformation are three terms often used interchangeably, and the concept of digitization was a general term. But in fact, they have different content in terms of coverage. Digitization is the conversion of information from a physical or analog form to a digital format. It refers "to creating a digital representation of physical objects or attributes", or in other words, it is fundamental and is the process of converting information from a physical format to digital one. Digitalization refers to enabling or improving processes by leveraging digital technologies and digitized data (Mateusz Hapon, 2020; Gupta, M.S., 2020).

This concept is concretized and interpreted in business. According to Gartner - a Global Research and Advisory Company, "Digitalization is the use of digital technologies to change a business model and provide new revenue and value-producing opportunities; it is the process of moving to a digital business" (Gartner Glossary). It means integration of digital technologies into everyday life by the digitization of everything that can be digitized and the use of data that has been transformed into digital format to improve business processes (PYSDEN, 2018).

In foreign literature, there are many different concepts of DT. In terms of technology-business-customer relationship, most define DT as the process of using digital technologies to transform existing traditional and non-digital business processes or create new processes or services that respond to market developments and customer expectations, radically changing the way businesses are managed and operated, and how value is delivered to customers; it brings business benefits such as improving customer experience, efficiency by reducing labor costs, and thus increasing competitiveness. (Whatfix; Daniel \& Christopher, 2018). If consider DT as a tool that changes people's lives, it is "a profound and accelerating transformation of business activities, processes, capabilities, business and organizational models to fully leverage the changes and opportunities brought by digital technologies and their impact across 
society in a strategic and prioritized way" (Demirkan et al, 2016).

Essence of DT is a business process transformation enabled by digitalization and digitalization technologies. Hence, it covers both digitization and digitalization (Gupta, M.S., 2020). In other words, DT is the application of digitized data, digitized processes and new technologies such as big data (Big Data), Internet of Things (IoT), cloud computing, etc. to shifting from the traditional operating model, leadership, working process, and culture to a new model based on the digital platform and around the digital environment.

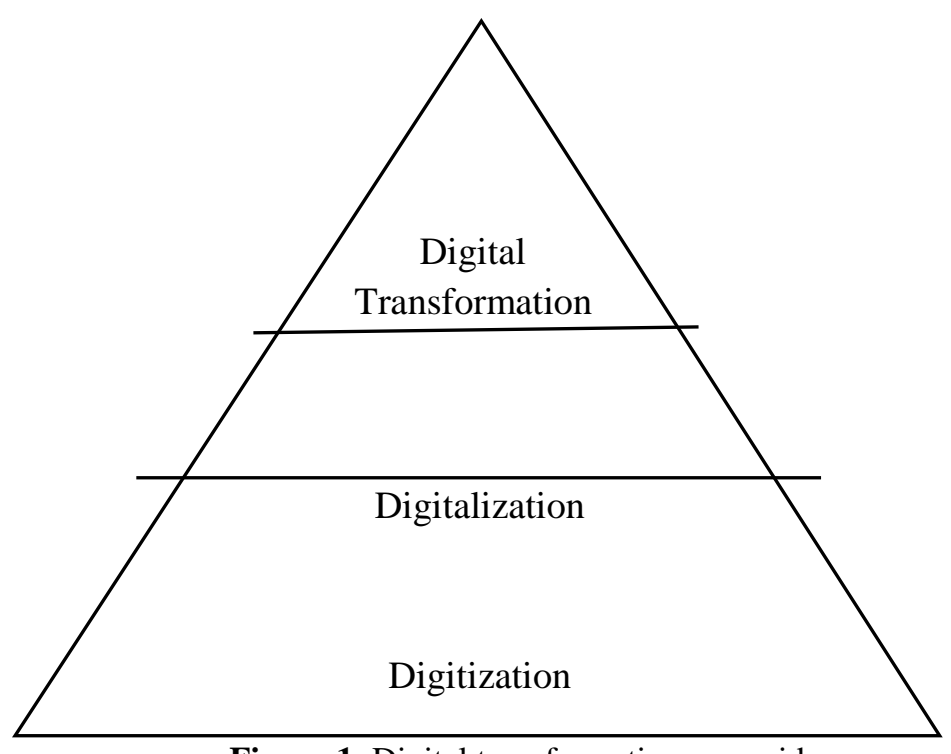

Figure 1: Digital transformation pyramid

Source: Gupta, M.S. (2020)

In terms of content, DT is considered to be the result of digitization and digitalization of economic and social processes (OECD, 2019).

As explained by Dobrica Savic (2019), there was a time when all three terms were used almost interchangeably, especially the two terms digitization and digitalization. Later, DT has an overarching connotation, in which digitization and digitalization are its constituent components and considers them to be the terms in the DT of an organization. For clarity, each term is reviewed through five facets: focus, goal, activity, tools, and challenges (Table 1).

The comparative analysis of the content presented in Table 1 shows that DT has an overarching meaning, including digitization and digitalization. It affects the organizational structure, leading to the adjustment or breaking of the old business model, bringing about significant organizational changes, especially in business strategy through applying digital technology.

Table 1: Digitization, digitalization, and digital transformation reviewed through five aspects: focus, goal, activity, tools, and challenges

\begin{tabular}{|l|l|l|l|}
\hline & Digitization & Digitalization & Digital transformation \\
\hline Focus & Data conversion & Information processing & Knowledge leveraging \\
\hline Goal & Change analog to digital format & $\begin{array}{l}\text { Automate existing business } \\
\text { operations and processes }\end{array}$ & $\begin{array}{l}\text { Change company's culture, the } \\
\text { way it works and thinks }\end{array}$ \\
\hline Activity & $\begin{array}{l}\text { Convert paper documents, } \\
\text { photos, microfilms, LPs, films, } \\
\text { and VHS tapes to digital format }\end{array}$ & $\begin{array}{l}\text { Creation of completely digital } \\
\text { work processes }\end{array}$ & $\begin{array}{l}\text { Creation of a new digital } \\
\text { company or transformation to a } \\
\text { digital one }\end{array}$ \\
\hline
\end{tabular}




\begin{tabular}{|l|l|l|l|}
\hline Tools & Conversion/encoding equipment; & $\begin{array}{l}\text { IT systems and computer } \\
\text { applications }\end{array}$ & $\begin{array}{l}\text { Matrix of new (currently } \\
\text { disruptive) digital technologies }\end{array}$ \\
\hline Examples & $\begin{array}{l}\text { Scanning paper-based } \\
\text { registration forms }\end{array}$ & $\begin{array}{l}\text { Completely electronic } \\
\text { registration process }\end{array}$ & $\begin{array}{l}\text { Everything electronic, from } \\
\text { registration to content delivery }\end{array}$ \\
\hline
\end{tabular}

Source: Dobrica Savic (2019)

The process of DT is happening in all sectors, and education as well as higher education is no exception. DT in HEIs is a process of technological and organizational changes, mainly due to the development of digital technology aimed at redesigning educational services and renovating the operational modes of higher education (Menendez et al, 2016; Kuzu, 2020). Changing teaching methods in a digital environment can be more beneficial for encouraging students to interact in learning (Helena \& Pedro, 2019). DT supports educational renovation by reducing lectures, increasing self-study and personalized learning, creating learning opportunities anywhere, anytime and contributing to creation of life-long learning society (To Hong Nam, 2020).

In order to survive and thrive in the digital age, HEIs need to apply information technology to their operations and adhere to a more comprehensive approach, in which the level of technology and digital literacy among students and faculty is particularly emphasized. It is not enough to just select a few areas of digitization. HEIs need to simultaneously carry out the following steps: digitizing data, digitizing educational processes and enhancing the digitization capacity of students and lecturers (PWC, 2018).

Looking back on history, the changes of HEIs have been being closely related to scientific and technical progress especially in the digital age. Since 1971, the problem that universities began to cease to be in a stable state was raised by Donald Schön in his book (1973). At the same time, the futurist Alvin Toffler (1971) confidently predicted that the information age would force universities to adapt to "accelerating pace of change", to preparing for the life-long learning. John, S.B. \& Paul D. (1996) have envisioned the appearance of new university model in the digital age when the application of information technologies, computer terminals and the use of the PC as a smart typewriter appeared in the library.

There is no complete definition of a digital university until now. Chris Jones' and Goodfellow, Robin (2012) have considered the term "digital university" as a discursive construction, empirical phenomenon and theoretical construct. And it suggests "a binary distinction between universities supported by new information and communication technologies, based on computing, and previous universities founded on analogue technologies up to and including television and telecommunications" (Jones, C., 2013). Regarding the content of digital university, Oslo Metropolitan University, Norway sets out the university's goals as: (1) providing new knowledge - new practice in the digital era and knowledge to solve social problems festival; (2) activating the power of innovation, ensuring digital adaptability through individual empowerment measures and modern infrastructure; (3) create profound new knowledge (personalized learning) among students, faculty and staff through the intelligent use of data; (4) saving time for students, faculty and staff through simplification, automation and standardization (OMU, 2018).

Considering the university as a corporation, DT in HEIs have gained special priority with the goal of changing teaching, learning and university governance models, which result in changes in all aspects such as teaching, infrastructure, curriculum, administration, research, business process, human resource, DT governance, information, and marketing (Maria, 2012). The formation of a digital university is also a result of the ongoing DT in education sector.

\section{Digital Library}

Since 1924, Harold L. Leupp considered that the library is the heart of the university as it is the place that provides knowledge for teaching and learning, and scientific research for lecturers/faculty and students (Harold,1924). Currently, academic publishing has moved beyond the paper-based stage, shifting from the digital development phase to the service-based stage in connection with the world's leading databases.

Waters D.J. (1998) based on ICT development, defined that "Digital libraries are organizations that provide the resources, including the specialized staff, to select, structure, offer intellectual access, interpret, distribute, preserve the integrity of, and ensure the persistence over 
time of collections of digital works so that they are readily and economically available for use by a defined community or set of communities". Gary Cleveland (1998) synthesized the opinions presented in the research of many scholars such as Graham (1995), Lynch and Garcia-Molina (1995), Chepesuik (1997) and argued that DLs have the following characteristics:

a) DLs are the digital face of traditional libraries that include digital collections and traditional, fixed media collections, whether the collections are in digital or paper format;

b) DLs will also include digital materials of other DLs;

c) DLs will include all the processes and services that are converted to digital platforms; and

d) DLs will serve the wider community through the network.

The concept of a DL has also been gradually improved with its existence. Joan M. Reitz (2004) in his Online Dictionary for Library and Information Science has given the definition of DL as "a library in which a significant proportion of the resources is available in machinereadable format (as opposed to print or microform), accessible by means of computers. The digital content may be locally held or accessed remotely via computer networks". Later, it is described as an online database of digital objects that may include text, still images, audio, video, digital documents and other digital media formats, or a library accessible via the internet (Savanur \& Nagaraj, 2004). So, it is also known as online library, internet library, virtual library, or digital collection.

The university DL definition introduced by Vincenzo M. and Fausto G. (2016) considered it as "a set of important resources, methodologies and tools appropriately organized to effectively support users of information of the university" and interpreted it as a natural extension of the DL, that is, taking advantage of the strengths and expanding the range of DL to serve all information users. This view is based on the argument that the DL is a place to store learning materials (related scientific works; references, lesson plans, personal information, etc.) relevant in the country and the world) and is a place through which access to other universities' DLs and other large databases in the country and the world (Kumbhar, 2014).
Emphasizing the technical features of DL in education, UNESCO (2006) defines it as "a collection of a very large number of digital objects, comprising all types of material and media, which are stored in distributed information repositories and accessed through national computer networks", and "a large collection of information that has been stored in digital form". It can include documents, images, sounds, and information gathered from ongoing events. University DL play an important role in teaching and learning because of two advantages: (1) reusability of resources: teachers can share digital resources in ways that are not possible with paper documents; (2) easy integration by students into learning and research works. However, the ease of integration is an opportunity, facilitating richer learning subjects, and a threat, making it easier for students to plagiarize.

The core of smart library in the era of Industry 4.0 is the ability to flexibly meet the needs of information users on the basis of digital information resources and online information services. (Vu Duy Hiep, 2018). Furthermore, digital materials on the internet can be used in educational applications, but will not be presented in the same controlled environment as materials in a DL. Therefore, lecturers need to introduce the information collected in the DL to focus students' activities and participation in controlling resource usage (Gary \& Hermann (1995).

According to the Vietnam Law No. 46/2019/QH14 on Libraries 2019, DL means "a library or a section of a library having information resources which have been processed and stored in digital formats for users to access and use via electronic devices and online" (Article 3). This given concept seems to cover the content of existing definitions of DL.

\section{METHODOLOGY AND MATERIALS}

The systematic literature review approach was applied in this study to briefly review the appearance and nature of the concepts of digitization, digitalization and DT, and the scholars' arguments on the concept, content and goals of digital universities and DLs.

The research team has collaborated with TQBL staff and users - students to conduct surveys on information users' habits, the types of documents they often refer to, and assess the current state of TQBL, especially its digital section of library and digital infrastructure; methods of 
comparative analysis and case study are used to analyze the survey data to find out the weak points and shortcomings of TQBL in particular and university libraries in HEIs in general, discuss the obtained results to propose useful recommendations to create a universities' DLs, keeping up with the ongoing trend of DL development in the world.

\section{CURRENT STATUS OF TA QUANG BUU LIBRARY}

To study current issues related to the development of university digital libraries, the research team applied a case study, selecting TQBL of HUST, the leading university among Vietnamese HEIs. Examining the TQBL current situation, the research team focuses on analyzing factors affecting library services such as information users' specialties, characteristics of digital information resources, access rights and digital infrastructure.

\section{Information Users' Specialties}

The main TQBL information users are all HUST staff, lecturers, students and other objects. As of January 2020, the University has 1,748 staff members and lecturers, more than 30,000 full-time students and more than 5,000 postgraduates, who are classified into 4 main groups, and each group has its own characteristics and information needs.

1) Leadership and administrative staff. This group includes the Board of Directors, heads and deputy heads of faculties and institutes. Although making up a small percentage of users, but they play an important role in the university operation. This users' group participates in both administrative work and scientific research or teaching, so they do not have much time to go to the library; their information needs are very diverse because they are both information users and information providers.

2) Lecturers and researchers belong to the group of highly qualified information users with high academic degrees involved in teaching, advising students, research projects and are the authors of lectures and textbooks. Therefore, they need updated information specialized in the fields of the works they undertake. This user group is accessing the database of university DL with high volume and frequency. Therefore, they are granted an account and use the Library's DL (e-resources) through the university's IP range.

3) Postgraduates and students. The information that postgraduates need is mainly specialized material relevant to their study program or research topic, such as: reference books, specialized journals, theses, etc. Most of them require a specific form of library service because they cannot be separated from their daily work.

Students are the main library users. New teaching methods and credit-based training in universities require lecturers to impart basic knowledge and advise students on research directions to promote the initiative and creativity of each student, encouraging them to visit the library regularly to complete weekly, monthly, semester or group assignments.

Table 2: Demands of student information users for different types of documents

\begin{tabular}{|l|c|c|}
\hline \multicolumn{1}{|c|}{ Type of documents } & Number of respondents & Proportion \\
\hline Paper - based resources & $132 / 171$ & $77,6 \%$ \\
\hline Endogenous electronic documents & 54 & $31,7 \%$ \\
\hline Online electronic database & 37 & $24,1 \%$ \\
\hline
\end{tabular}

Source: TQB Library, survey in May 2019

The users' survey conducted by TQBL in 2019 shows that students are mainly TQBL users, accounting for $90 \%$. However, most of them need paper-based learning materials (Table 2). Only nearly $35 \%$ of respondents regularly use digital libraries and online resources (Table 3). 
Table.3: Level and type of library materials used by students

\begin{tabular}{|l|c|c|c|c|c|c|}
\hline \multicolumn{1}{|c|}{ Type of materials } & \multicolumn{2}{c|}{ frequently } & \multicolumn{2}{c|}{ Sometimes } & \multicolumn{2}{c|}{ Seldom } \\
\hline & $\begin{array}{l}\text { Number of } \\
\text { respondents }\end{array}$ & $\%$ & $\begin{array}{c}\text { Number of } \\
\text { respondents }\end{array}$ & $\begin{array}{c}\text { Number of } \\
\text { respondents }\end{array}$ & $\%$ \\
\hline Specialized References & $111 / 171$ & 65.3 & $33 / 171$ & 19,4 & $26 / 171$ & 15.3 \\
\hline Textbooks & 132 & 77.7 & 22 & 12.9 & 16 & 9.4 \\
\hline Master's and Doctoral Theses & 57 & 33.6 & 22 & 12.9 & 91 & 53.5 \\
\hline Economic and social theme & 55 & 32.4 & 24 & 14.1 & 91 & 53.5 \\
\hline Literary and artistic works & 54 & 31.8 & 20 & 11.7 & 96 & 56.5 \\
\hline Foreign language, informatics, & 81 & 47.7 & 20 & 11.7 & 69 & 40.6 \\
\hline Online database, Ebrary & 59 & 34.7 & 30 & 17.6 & 81 & 47.7 \\
\hline
\end{tabular}

Source: TQB Library, survey in May 2019

The main reason is that they have not been granted an account for remote access to online electronic databases and full-text viewing rights and their skills in searching for information on the internet are not yet complete, which affects their online learning skills and personalized learning.

4) Group of non-university users. In addition to university' staff, lecturers, and students, TQBL also serves non-university users. To use the library, this private users group must register and receive a library card. Their information needs are also very diverse in all areas. Therefore, it is necessary to grasp their information needs to proactively introduce and advise appropriate products and services as well as how to exploit and search for information in TQBL.

In order to serve the quality of information provision, university library must conduct a review and assessment of the above information user groups' characteristics and demand for information and make measures to meet their multiple needs.

\section{Characteristics of Digital Information Resources in $T Q B L$}

According to the Law No. 46/2019/QH14 on Libraries 2019, an information resource is defined as "a collection of documents and data of various types, including print documents, handwritten documents, audio-visual documents, digital documents, microform documents including microfilm and microfiche, special documents for people with disabilities, and other documents and data". By definition, TQBL information resources can be divided into 2 main sections.

Section 1: traditional information resources - paper-based documents. This section includes traditional literature by specific disciplines and traditional literature by document type as illustrated in Figure 2 and Table 4. Since HUST is considered the largest university of science and technology in the country, its library's information resources mainly consist of scientific and technical literature, accounting for about $81 \%$, and social science literature comprises $19 \%$ based on the TQBL statistics. 


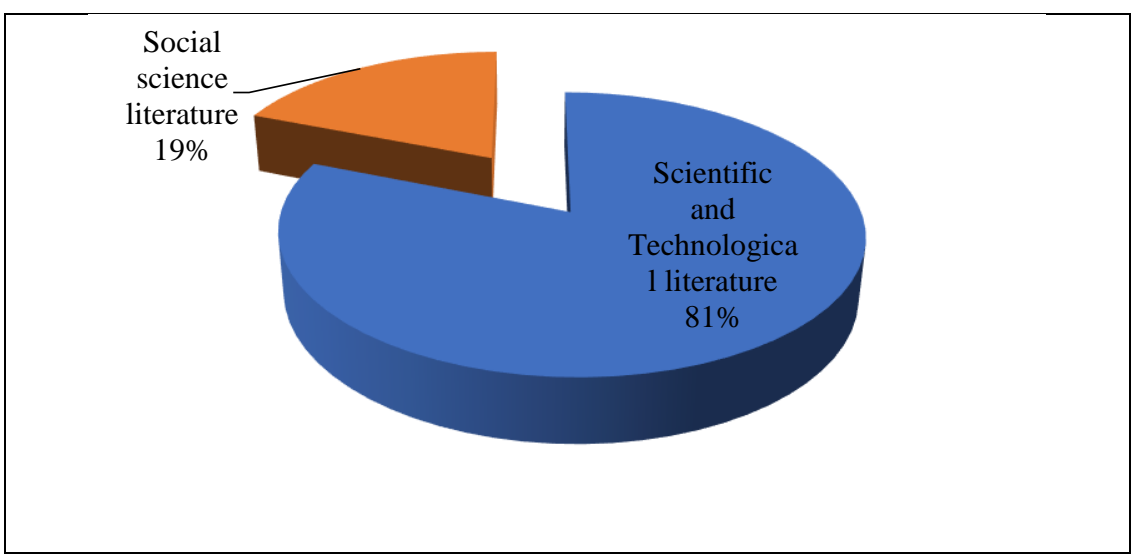

Figure 2: Traditional paper-based literature by subjects

Source: Ta Quang Buи Library, 2019

Table 4: Traditional literature proportion by type

\begin{tabular}{|l|c|c|}
\hline \multicolumn{1}{|c|}{ Type } & Total (unit) & Proportion \% \\
\hline Textbooks & 231,153 & 34.74 \\
\hline Books & 162,101 & 24.37 \\
\hline Newspapers, journal & 252,329 & 37.91 \\
\hline Theses and dissertations & 19,851 & 2.98 \\
\hline
\end{tabular}

Source: Ta Quang Buи Library, 2020

Section 2: digital information resources including digital documents and digital collections database developed by TQBL (bibliographic database: more than 60,000 records and full-text database with more than 13,000 records) and databases ordered by projects or through Union Library (ScienceDirect Database, ProQuest Central Database, Ebrary Academic Complete, CD, floppy disk including 16,000 records in 15,000 discs. The current structure of the TQBL endogenous sources Database includes three components: electronic lectures, doctoral and master theses arranged by specialties (Figure 5, in blue). Digital resources of TQBL are still very limited in quantity and type compared with traditional section.

Digitizing documents and building digital collections is the optimal choice for long-term preservation of rare original documents. It can be said that the core of DL is a digital repository or digital collections, because DL is essentially a digitized information repository, structured for easy access over computer networks or telecommunications network (Jie \& Bao, 2012). Being the largest university of science and technology in the country, HUST always attaches great importance to the quality of training and scientific research and considers it a top criterion in its activities. Stemming from that goal and realizing the importance of endogenous digital resources, TQBL has persistently digital collections from the university's endogenous sources over the years.

Since 2009, TQBL has used the open source software Dspace to build and access digital collections with more than 13,000 digital documents in 3 collections: master and doctoral theses' collection defended at HUST; electronic lecture collection includes electronic lectures written or compiled by university faculty; and a collection of articles, scientific publications and research works conducted by university staff and students.

\section{Access rights}

An open service policy for endogenous materials and which has granted full text access to all HUST' information user is being developed by TQBL. However, the library's server is frequently overloaded due to its old age that limits concurrent remote access. For remote access, users need to contact with the TQBL manager for an account and password to be able to log in to view the full text. Therefore, non-university users with remote access to this resource are restricted, and they can only view the bibliography (first 16 pages), while HUST staff and students can view the full text of endogenous 
materials directly at the TQBL or the university's IP range computers. In the coming time, TQBL will continue to submit to the university Board of Directors to clarify the issue of copyright between the authors and the library to provide open access to the source without violating Law on Copyright.

To help university staff, faculty and students make more use of other useful e-resources, TQBL has collaborated with other universities to share the Ebrary Academic Ebook database, and join the Alliance Association of Vietnam Electronic Resource Libraries using the same Proquest Central Common Database; TQBL is one of three university libraries that have free access to the SienceDirect database under the auspices of the Ministry of Science and Technology.
In addition to the collections built by TQBL and shared purchased databases, it also partners with international publishers to test the use of their electronic databases such as IGI Global, ASME, Taylor \& Francis databases, and links with electronic information resources from the Information Centers of the Hanoi National University Library and the Library of Hanoi University of Culture, etc.

\section{Library Digital Infrastructure}

The internal assessment of the library staff on the state of the library's general infrastructure shows that it is maintained in good condition, including four indicators of digital infrastructure such as computer, internet and intranet systems and server.

Figure 3: library staff evaluation on the current state of the library general infrastructure (in \%)

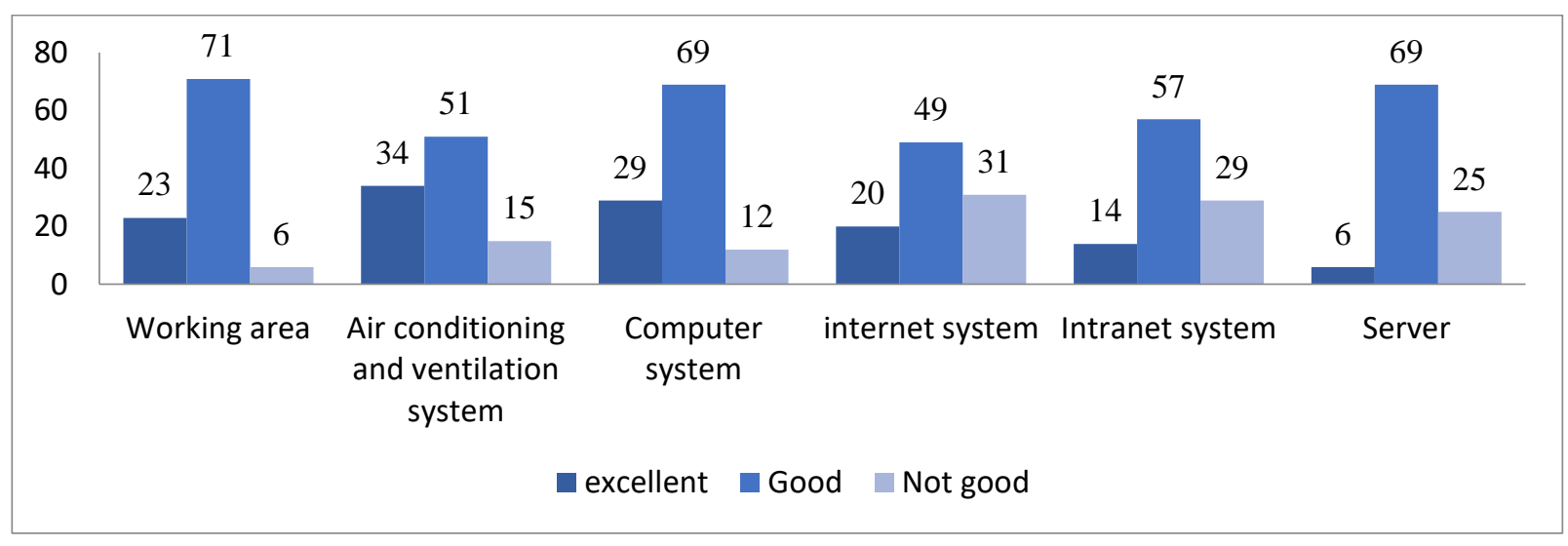

Source: Library staff survey in 2019

TQBL's digital infrastructure refers to hardware, software and data transmission line.

- Hardware. The library' Dell R720 server used since 2016 is not configurable to meet the needs of large concurrent access of users; RAM overflow leads to jam or loss of connection when there is a lot of traffic to the server.

- Software is one of the indispensable and increasingly important elements to develop digital resource. TQBL is one of three libraries in Vietnam that use Sierra management software and Dspace considered as most user-friendly, suitable for libraries and information users. The library always plans to upgrade the software to manage digital resources.

\section{Library Human Resources}

Librarians are an indispensable human resource in any library, whether it is a traditional library or a DL. They play an important role, determining the quality and efficiency of the library's operation. The DL development requires a human resource capable of working in a network environment with digital data sources and network-connected computer devices. In other words, human resources in the digital environment need to be able to select, add, process, organize, store, preserve, secure and archive digital collections, that is, create digital collections, digital products and organize modern digital services for easy exploitation anytime, anywhere (Sreenivasulu, 2000).

Ta Quang Buu Library has 33 staff as of 2020, a decrease of two compared to 2019. However, there are only 5 people, including 01 ICT master, 04 masters who work in the digital section of the library and are in charge of installing software, repairing computers, connecting to the network, managing digital collections, receiving and cataloging endogenous digital documents. 
Figure 4. Chart of TQB librarian's ability to use different software (in \%)

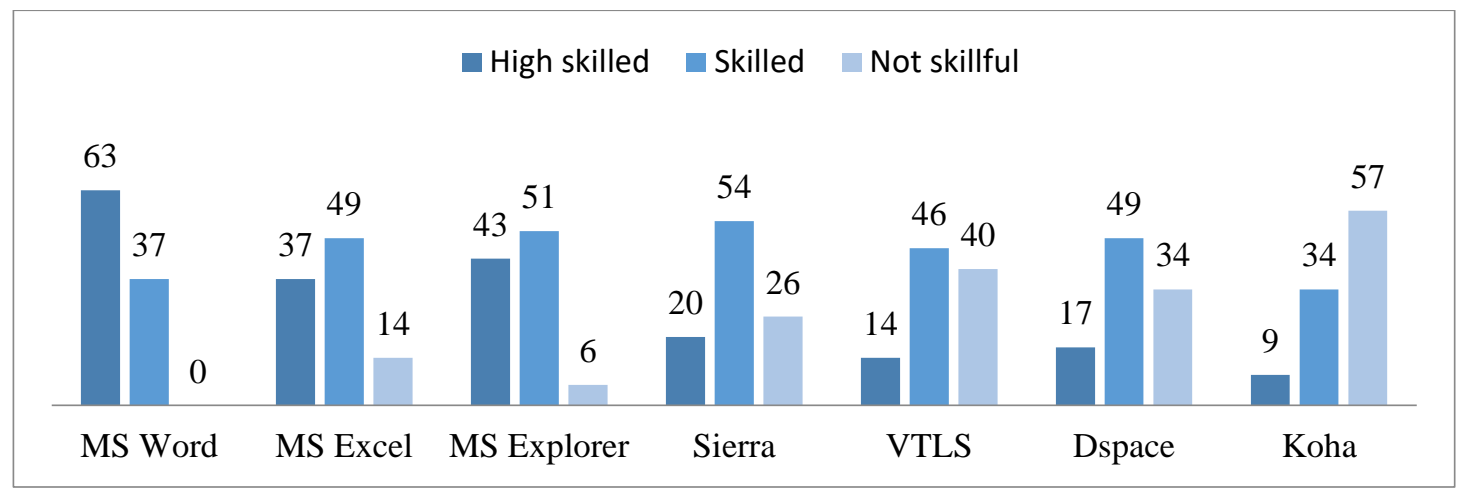

Source: Ta Quang Buu Library, 2020

The management of the DL, ensuring the smooth operation of the library, providing the ability to access digital resources to users most effectively is the librarians' function. However, the limited proficiency in using library software as shown in Figure 4 cannot fully meet the job requirements. Moreover, although the digital section of TQBL is an important part, but the number of librarians working there is only 5 people, too small to perform their duties.

\section{DISCUSSION AND RECOMMENDATION}

The problems faced by TQBL in the case study on the status of TQBL reflect the prevailing situation of other university libraries, showing a lot of experience for university libraries and suggesting a problem-solving approach to become a DL in the digital age. As one of the important HUST units with the desire to become a leading DL among university libraries in Vietnam, TQBL needs to implement various solutions to solve the challenges and inadequacies that affect the development and service quality of the library.

\section{Human Factor}

The human factor is the most important in DL development. University leadership support is a prerequisite for solving the shortage of ICT professionals among library staff and other problems related to human factor.

The support of leaders of universities is reflected in such aspects as: (a) funding the development of digital information resources and the upgrading material technical facilities for library operation; (b) formulating regulations on the submission of endogenous sources to the library; (c) creating conditions for librarians to study and improve their professional qualifications.

The role of librarians is affirmed in any library, whether it is a traditional library or a local library because they have a direct influence on the creation and preservation of digital collections, service quality and efficient operation of the library. It is necessary to create conditions for librarians to improve their working skills and comprehensive qualifications, focusing on on-the-job training and the librarian participation in training courses, conferences, meetings and seminars organized by Library Information Centers.

Information user training implies instruction for library users to help them know the organization, operation of library services and effectively access information resources. User skills training content should focus on organizing online support through instructions in the form of text, images, videos or seminars, conferences and through user feedback to capture their information needs to improve the library's products and services.

\section{Creating and Developing Digital Collections}

Creating and developing digital collections based on exogenous and endogenous digital information sources of disciplines and training majors of HUST are considered a synchronous method to enrich TQBL digital information sources. Compared with traditional information sources, TQBL electronic information sources account for a low proportion. TQBL plans to collect and develop its own DL, concentrating on digitizing books, collecting endogenous information sources from other centers and 
open libraries. This is a useful experience in developing DL for any university library. electronic lectures, doctoral theses and master's theses arranged by specialties (Figure 3, in blue).

Current structure of the endogenous database of the HUST's TQBL includes only three components:

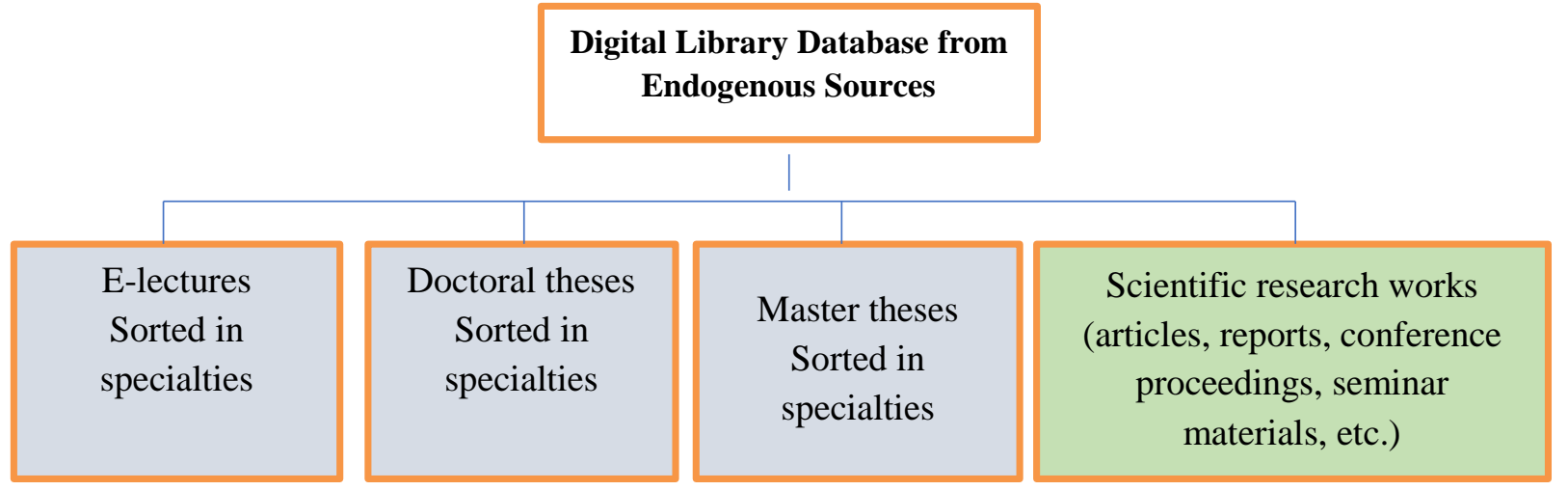

Figure 5: Structure of the Digital Library Database from endogenous sources

Source: Ta Quang Buu Library

However, it should be noted that an extremely large endogenous source is scientific research works, theses, reports, and conference proceedings, seminar materials compiled or published by the staff, lecturers, researchers and students stored somewhere in the faculties, institutes, and centers of the university and not yet collected by the library. Many textbooks and learning materials brought into the library are still in paper based form. They need to be digitized to enrich the library's endogenous digital archives. Therefore, the research team proposes to add a fourth component (Figure 5, in brown) to the endogenous source structure.

Along with collecting endogenous sources, enriching the library with exogenous digital resources should be considered as a practical measure. The survey shows that $50 \%$ of information users have a need to refer to digital textbooks and reference books that cannot be found in the e-library of TQBL. The development of exogenous digital resources for the library can be addressed by:

a) funding for the purchase of electronic databases. Libraries need to select high-quality databases verified with international standards such as IEEE, WoS, Scopus, etc.

b) Searching and collecting free, high-quality digital materials from open learning sources such as digital materials, digital collections of monographs, scientific research results, textbooks, lectures, articles in specialized journals, scientific conference proceedings, theses, graduation projects, internship reports, etc. This saves money and time to enrich the library's digital archives.

c) Sharing digital resources. In the context of limited funding, exchanging and sharing digital resources with other information centers and libraries is a very important and necessary measure to enrich digital resources. However, this activity needs to be concretized with an appropriate policy to avoid violating Law on Copyright.

\section{Digital Infrastructure Upgrade Policy}

Regularly upgrading the digital infrastructure of the library should be taken seriously to prepare for future information needs. TQBL's statistics show that the number of online visits to the library digital database is relatively large with nearly 3 million in 12 months. However, Dell R720 server is outdated and often causes network congestion; Dspace software frequently encounters overload problems, resulting in interrupted user service. Therefore, HUST and TQBL leaders should have a strategy for a long-term funding and policies to provide new library equipment and regularly upgrade hard ware and software of library computer system.

Besides, it is necessary to make a policy on exploiting digital TQBL's resources in the near future because at this time only users of the university can have free access to exploit digital resources within HUST's IP range. This 
limitation somewhat hinders the accessibility of digital resources by non-university users. Legal issues of author's copyright related to materials collected by TQBL clarified to ensure that the library does not infringe copyright; there should be a plan to provide open access to endogenous sources in the future.

\section{Building Database for E-learning}

The emergence of digital university and digital library concepts and new forms of training and learning in the context of the explosive ICT growth of in Industry 4.0, contributes to lifelong learning and personalized learning and allows creating virtual classrooms in the form of Elearning, where learners can learn anywhere, anytime. Elearning is considered a new teaching method that supplements and supports traditional classroom training methods. To serve this type of class, the library must build a digital database and multimedia electronic learning materials and diversify types of literature and supplement online learning resources for E-learning. Therefore, the HUST's TQBL must continue to renovate computer equipment throughout the University with high-speed broadband Internet connection. A group of professional measures should be continued, that is:

- Building a Journal Citation Database;

- Diversifying and improving the quality of library information services;

- Organizing thematic information provision service;

libraries;

- Sharing information resources with other

- Organizing selected information dissemination service.

\section{Conclusion}

The formation of DL is considered as a succession and development of the traditional library on the basis of DT that becomes an inevitable part of the digital society and common development trend of university libraries around the world in the digital era. The rich digital information and digital learning materials provided by DL helps users to study and research anytime, anywhere, formatting lifelong learning and personalized learning. For any HEI, the Library is considered the heart and plays a particularly important role. The TQBL case study shows a number of issues that need to be addressed such as analyzing information users, improving librarians' capacity and skills, developing digital sources, funding IT infrastructure development as well as building database for E-learning in long-term. The research team also realizes that it is necessary to study more deeply and specifically on the service quality of digital libraries and the application of assessment models to develop the university DL system in Vietnamese HEIs.

\section{ACKNOWLEDGMENT}

This work was supported by the School of Economics and Management of Hanoi University of Science and Technology, Hanoi, Vietnam (Project No. T-2021-PC054): "Quality assessment of Ta Quang Buu Digital Library, s service".

\section{REFERENCES}

[1] Alvin Toffler (1971). Future Shock. A Bantam Book, January 1, 1980.

[2] Brown, John Seely \& Paul Duguid (1994). Borderline Issues: Social and Material Aspects of Design. Human-Computer Interaction, 9(1): 1-36.

[3] Bui Thi Nga, Le Vu Toan, Luu Duc Long (2020). Higher education: Opportunities and challenges in digital transformation. mic, https://m.mic.gov.vn/Pages/TinTuc/143493/Gia o -duc-dai-hoc--Co-hoi-va-thach-thuc-inchuyen-doi-so.html

[4] Chepesuik, R. (1997). The future is here: America's libraries go digital. American Libraries, Vol. 2(1), 47-49.

[5] Daniel R. A. Schallmo \& Christopher A. Williams (2018). Digital Transformation Now! Guiding the Successful Digitalization of Your Business Model. Springer Briefs in Business. DOI: https://doi.org/10.1007/978-3-319-728445

[6] Daniel-Zoe J., Victor L., Lawrence Ch.,Huimin, $\mathrm{Ng}$ (2017). Unlocking the Economic Impact of Digital Transformation in Asia Pacific. White Paper. November, 2018

[7] Demirkan, Haluk \& Spohrer, James \& Welser, Jeffrey. (2016). Digital Innovation and Strategic Transformation. IT Professional. IT Pro November/December 2016, 14-18. https://ieeexplore.ieee.org/stamp/stamp.jsp?tp= \&arnumber $=7763741$

[8] Gartner Glossary. Digitalization. gartner. available https://www.gartner.com/en/informationtechnology/glossary/digitalization

[9] Gary Cleveland (1998). Digital Libraries: Definitions, Issues and Challenges. UDT Occasional Papers, vol. 8, March, 1998, 1-8. https://archive.ifla.org/udt/op/udtop8/udtop8.pdf

[10] Gary, M \& Hermann, M (1995). The Roles of Digital Libraries In Teaching and Learning. Commun ACM. Vol.38, 67-75. DOI: $10.1145 / 205323.205345$ 
[11] Graham, P.S. (1995). Requirements for the digital research library. URL: http://aultnis.rutgers.edu/texts/DRC.html

[12]Gupta, M.S. (2020 ). What is Digitization, Digitalization, and Digital Transformation? ARC advisory Group, March 24, 2020; https://www.arcweb.com/blog/whatdigitization-digitalization-digital-transformation

[13] Harold L. Leupp (1924). The Library The Heart of the University. In Bulletin of the American Library Association. Vol. 18, Paper and Proceedings of the Forty -Sixth Annual meeting (August 1924), pp. 193-197.

[14] Helena,S.,João,B.,Rui Pedro,M. (2019). Digital transformation in higher education: the use of communication technologies by students. In Procedia Computer Science, Vol.164, 2019, Pages 123-130, https://doi.org/10.1016/j.procs.2019.12.163

[15]Jie Suna \& Bao-Zhong Yuanb (2012). Development and Characteristic of Digital Library as a Library Branch. 2012 International Conference on Future Computer Supported Education, IERI Procedia 2 (2012 ) 12 - 17; https://core.ac.uk/download/pdf/82300967.pdf

[16]Joan M. Reitz (2004 ). Online Dictionary for Library and Information Science. https://products.abcclio.com/ODLIS/odlis d.aspx

[17] John \& Bedoya, Branch \& Burgos, Daniel. (2020). Digital Transformation in Higher Education Institutions: A Systematic Literature Review. Sensors, $20 \quad$ (11): 3291. 10.3390/s20113291

[18] Jones, Chris \& Goodfellow, Robin. (2012). The "Digital University": Discourse, Theory, and Evidence. International Journal of Learning and Media. 4. 59-63. 10.1162/IJLM_a_00103

[19] Jones, Chris (2013). The digital university: a concept in need of definition. In Book "Literacy in the Digital University", 1st Edition, Routledge, 2013

[20] Kumbhar, R (2014). Academic Library's Responses to the Emerging Trends in Higher Education. DESIDOC Journal of Library \& Information Technology, 34(6). https://doi.org/10.14429/djlit.34.6.6878

[21] Kuzu, Ö.H. (2020). Digital Transformation in Higher Education: A Case Study on Stra-tegic Plans. Vysshee obrazovanie v Rossii // Higher Education in Russia. Vol. 29, no. 3, pp. 9-23. DOI: https://doi.org/10.31992/0869-3617-201929-3-9-23

[22] Lynch, CA. and Garcia-Molina, H. (1995). Interoperability, scaling, and the digital libraries research agenda: a report on the May 18-19,
1995 IITA Digital Libraries Workshop. URL: http://www-

diglib.stanford.edu/diglib/pub/reports/iitadlw/m ain.html

[23] Mateusz Hapon (2020). What Is the Difference Between Digitization, Digitalization and Digital Transformation? updated in Sep 28, 2020. Netguru - Polish Software Development and Consultancy Company. https://www.netguru.com/blog/digitization-anddigitalization

[24] Menendez F. A., Maz-Machado, A., LopezEsteban, C. (2016). University Strategy and Digital Transformation in Higher Education Institutions. A Documentary Analysis. International Journal of Advanced Research, vol. 4, no. 10,2016, pp. 2284-2296

[25] OECD (2019). Going Digital: Shaping Policies, Improving Lives. OECD Publishing, Paris, DOI: https://doi.org/10.1787/9789264312012-en.

[26] OMU [Oslo Metropolitan University] (2018). The digital university of the future Strategy for digital transformation 2018-2024. https://ansatt

[27]PWC (2018). The 2018 digital university. Staying relevant in the digital age. PricewaterhouseCoopers

[28] PYSDEN (2018). What is Digitalisation ?. Pysden Solitors Press Release 250. https://www.pysdens.com/wpcontent/uploads/250-DIGITISATION-andDIGITALISATION.pdf

[29] Savanur, Kiran \& M N, Nagaraj. (2004). Design and Implement of Digital Library: an overview. http://eprints.rclis.org/8432/1/ASSIST.pdf

[30] Savić, Dobrica. (2019). From Digitization, through Digitalization, to Digital Transformation. 43/2019. 36-39.

[31] Schön, Donald (1971). Beyond the Stable State. New York, NY: Norton Library, 1973.

[32] Sreenivasulu, V. (2000). The role of a Digital Librarian in the Management of Digital Information Systems (DIS). The Electronic Library, Volume 18 (1), 2000, 12-20. http://eprints.rclis.org/6502/1/role-DL-DIS.pdf

[33] To Hong Nam (2020). Digital transformation in the field of education and training: Current status and solutions. Journal of Information and Communication Magazine, issue 2, April, 2020.

[34] Torres-Ruiz, Miguel \& Moreno, Marco. (2019). Challenges and Opportunities in the Digital Transformation of the Higher Education Institutions: The Case of Mexico. 10.1108/9781-78973-627-420191012.

[35] UNESCO (2006). Digital Libraries in Education. Specialized training course. Study Guide. UNESCO Institute for Information 
Technologies in Education. https://iite.unesco.org/pics/publications/en/files/ 3214563.pdf

[36] Vincenzo M. \& Fausto G. (2016). Foundations of Digital Universities. Cataloging \& Classification Quarterly. DOI: 10.1080/01639374.2016.1245231

[37] Vu Duy Hiep (2018). Libraries in the era of industrial
4.0 . http://trungtamtttvnth.vinhuni.edu.vn/thuvien/seo/thu-vien-trong-ky-nguyen-cach-mangcong-nghiep-40-85654.

[38] Waters, D.J. (1998). What are digital libraries? CLIR Issues, July/August, 1998. URL: http://www.clir.org/pubs/issues/issues04.HTML

[39] Whatfix. What is Digital Transformation? whatfix, https://whatfix.com/digital- 